\title{
DIFERENCIACIÓN Y DELIMITACIÓN MUNICIPAL DE LOS MODELOS TURÍSTICOS EN LA PROVINCIA DE ALICANTE ${ }^{1}$
}

\author{
Daniel Díez Santo \\ Universidad de Alicante
}

\begin{abstract}
RESUMEN
El artículo trata de exponer una nueva metodología para la diferenciación y la delimitación territorial de los espacios turísticos litorales e interiores en la provincia de Alicante. Por la imposibilidad de establecer una clasificación simple basada únicamente en municipios de vocación turística litoral e interior. Se propone por la heterogeneidad del espacio de trabajo crear un tercer grupo formado por los municipios inmediatos al litoral, el cual a su vez, queda subdividido en municipios accesorios del litoral y municipios de ocupación ocasional surgidos como respuesta a la movilidad de los flujos turísticos litorales.

La metodología empleada se basa en la creación de capas de información para la posterior superposición mediante la utilización de SIG. En este sentido, se ha tenido en cuenta la presencia de fachada marítima dentro de los términos municipales, el análisis de la promoción turística del interior en el espacio litoral, la estructura provincial de la oferta de alojamiento y la presencia y consolidación de los programas europeos para el desarrollo rural (PRODER 2 y LEADER +).
\end{abstract}

Palabras clave: Diferenciación territorial, turismo interior, fachada litoral, promoción, oferta de alojamiento, desarrollo rural.

\begin{abstract}
The article tries to expose a new methodology for the differentiation and the territorial boundary of the coastal and inner tourist spaces in the province of Alicante. By the impossibility to establish a simple classification, merely on the basis in coastal and inner tourist vocation municipalities. It is proposed by the heterogeneity of the work space to create a third group formed by the immediate municipalities to the coast, which as well, is subdivided in accessory municipalities of the coast and municipalities of occasional occupation arisen as an answer to the mobility of the coastal tourist flows.
\end{abstract}

1 Este artículo es una síntesis del Proyecto de Suficiencia Investigadora: "La Delimitación Territorial del Turismo de Interior en la Provincia de Alicante" realizado por Daniel Díez Santo y dirigido por Dr. D. José Fernando Vera Rebollo. Instituto Universitario de Geografía. Universidad de Alicante. 
The used methodology is based on the creation of layers of information for the later superposition by means of the use of GIS. In this sense, it has being taken into account the presence of marine facade within the municipal terms, the analysis of the interior tourist promotion in the coastal space, the provincial structure of the lodging's offer and the presence and consolidation of the european programs for the rural development (PRODER 2 and LEADER + ) and the determination of the Maximum Mobility Area of the Coastal Tourist Flows.

Key words: Territorial differentiation, inner tourist, littoral facade, promotion, lodging offer, rural development.

\section{Introducción}

El turismo como logro social de masas es un hecho que no se puede pasar por alto, sobre todo si abordamos el tema desde el caso de la provincia de Alicante. El turismo en esta provincia es un factor extraordinario de desarrollo económico, ya que actúa como verdadero motor socioeconómico de algunos de los municipios alicantinos más representativos y generadores de riqueza.

El turismo en la provincia de Alicante ha crecido a pasos agigantados desde los años 60 del siglo pasado, siguiendo si bien, según casos, modelos de implantación y desarrollo del todo variopintos. De momento, la mayor concentración de esta actividad se ha localizado en el litoral, asociada al altamente productivo binomio sol-playa. En estos momentos, podemos señalar que la Costa Blanca, es un verdadero foco de atracción turística a nivel nacional e internacional, que aún siendo un destino maduro, sigue tratando de innovar y abrir mercados, ofreciendo al turista nuevas experiencias vacacionales dotadas de una heterogénea oferta complementaria.

Los dos hitos turísticos fundamentales del litoral alicantino, expendedores de modelos sorprendentemente contrapuestos a pesar de su relativa proximidad geográfica, son Torrevieja y Benidorm. Torrevieja ha apostado por un consumo exacerbado de su suelo, llegando a devorarlo totalmente salvo algunos resquicios conservados por su impronta medio ambiental. «El espacio deja de ser factor de producción para convertirse en objeto de consumo; cambian las prioridades de usos del suelo y de los demás recursos naturales, a la vez que la línea litoral se va congestionando ante la avalancha y se produce una transformación radical no sólo del espacio sino también de los modos de vida, hábitos, etc (...) El turismo se enseñorea del espacio y orienta los demás sectores productivos a sus exigencias, con una masiva terciarización de la población activa pero, sobre todo, un engrosamiento espectacular y artificial del subsector construcción y de otros subsectores dependientes de él, todo ello en función del auge urbanizador. La morfología del núcleo cambia radicalmente, a la vez que se expande a lo largo del eje costero» (Vera, 1984: 123). De este modo, se llega al extremo constituyéndose verdaderas colonias integrales de tipo Resort, surgidas de la nada y totalmente autosuficientes. Este modelo sigue creciendo y extendiendo sus prolongaciones hacia municipios que le son aledaños e insertos en el Área de Máximo Desplazamiento de los Flujos Turísticos Litorales (AMDFTL) ${ }^{2}$, todo sea dicho, cada vez ampliada mayormente gracias a la mejora de las vías de comunicación.

El caso de Benidorm implica también un notabilísimo crecimiento, irremediablemente en el plano horizontal, pero sobre todo en el plano vertical. Se ha apostado por consumir

2 Área de Máximo Desplazamiento de los Flujos Turísticos Litorales (AMDFTL): Franja ubicada entre la línea de costa y el espacio interior, sobre la cual, los turistas alojados en el medio litoral están dispuestos a invertir sus desplazamientos en busca de una oferta complementaria. 
el suelo mínimamente, a cambio de un impacto paisajístico costero a los pies de la Sierra Helada, que no deja impasible a nadie.

No nos vamos a posicionar ni a favor ni en contra de ninguno de estos dos modelos, ambos disponen ya para el caso de fervorosos defensores y críticos detractores, sólo debemos pensar que todo progreso trae consigo un precio que se debe pagar ineludiblemente. Para ello, antes de apostar por un modelo de crecimiento, debemos conocer cuál va a ser el precio a pagar por el desarrollo y a dónde nos va a llevar ese proceso a medio y largo plazo. Sirva al menos para algo, la notabilísima experiencia adquirida en nuestra provincia a cerca de la implantación de procesos turísticos, para no reincidir en errores bajo la excusa del apostar sin saber el resultado. Ya sabemos a donde llevan la mayor parte de los caminos, de modo que vamos a trabajar para buscar la senda del sentido común, aunque para ello se tenga que decir «no», no debe usted apostar por la actividad turística a cualquier coste.

Este preámbulo nos sirve para enmarcar la situación actual que nos lleva a buscar alternativas complementarias al turismo litoral. El turismo de interior, que no siempre rural, cada vez más se está gestando como una alternativa al turismo litoral. Para algunos dirigentes, claramente dependiente del modelo litoral, cual simple complemento. Pero para otros, sea nuestra humilde opinión, como un ente independiente capaz de generar atracción por si mismo, de complementariedad ineludible con el turismo litoral, pero no en un sólo sentido, sino mutua y recíproca.

«(...) la provincia de Alicante, con destinos turísticos litorales en fase de madurez y áreas de interior cuyos recursos no poseen un atractivo de gran rango para promover desarrollos turísticos endógenos, la complementariedad entre ambos espacios, entre la oferta instalada en el litoral y los recursos del interior, permite el desarrollo de estrategias de cualificación de los espacios turísticos, al incorporar esos espacios del traspaís, que poseen recursos adecuados a las nuevas tendencias de los mercados turísticos (...) Con el desarrollo de esta dialéctica litoral-interior se avanza hacia un doble objetivo: - el desarrollo turístico de espacios interiores, mediante la puesta en valor de los recursos interiores y, - la diversificación de los productos litorales, mediante la inserción de elementos de oferta ajenos y que entroncan directamente con los nuevos gustos de la demanda» (Baños, 1998: 99-100).

A pesar de ello, debemos entender que; «No es nada probable, ni deseable, que los espacios rurales se conviertan en el destino alternativo de los turistas del litoral. Esta posibilidad se aleja de toda coherencia con respecto a un desarrollo sostenible del turismo en espacios rurales. Del mismo modo que no guarda ninguna relación con la situación actual del mercado turístico» (Ivars, 2000: 85). Pero por otro lado, tampoco podemos pensar en el turismo de interior, como la negación del turismo litoral. Esta claro que ambos productos buscan fines similares, pero parten de estrategias contrapuestas para llevarlos a término.

«El turismo de interior puede constituir un buen término para definir una actividad turística de interior, distinta del turismo litoral, cuando aquella se ubique tanto en espacios rurales como urbanos (ciudades históricas de interior, por ejemplo), con lo que se convierte en un término adecuado por su carácter globalizador. Por otra parte, puede caerse en la tendencia de considerar el turismo de interior como un turismo dependiente del turismo costero, interpretación que nos parece equivocada. En cambio, las relaciones de complementariedad entre ambos espacios revisten un indudable interés» (Ivars, 2000: 77).

El turismo de interior, se piensa más como un complemento de la economía de los municipios en los que se implanta, y no como motor fundamental para el desarrollo socioeconómico, aunque tampoco es preciso que sea así, y de ello sobran también los ejemplos, sólo citar el caso del municipio castellonense de Morella. 
El turismo de interior, debe partir de la madurez del saber turístico, de modo que se tenga a priori muy claro lo que se quiere hacer. La tendencia que se está llevando a cabo tiene sus bases bastante consolidas y definido hasta donde se quiere llegar. Desde la administración autonómica y la mayor parte de las entidades municipales, se está apostando al menos aparentemente por un turismo selectivo, de calidad y respetuoso con el medio ambiente. Además, se está intentando introducir de un modo muy suave, paulatinamente, para ver lo que sucede, porque a pesar de todo sigue siendo un poco como una experiencia realizada sobre un medio tremendamente reactivo, es decir, una sociedad muy familiar y no acostumbrada a demasiados trasiegos de visitantes que alteren su tranquilidad. Por otro lado, va a ser fundamental evitar el rechazo, ya que si este se produce la inserción de esta actividad económica será irremediablemente inviable en su aplicación. A pesar de ello, siempre hay excepciones que van a confirmar la regla, como puede ser el caso de Castalla, que está implantando en su municipio cuantas propuestas urbanísticas va recibiendo, nada importa más que el desarrollo.

En definitiva, el turismo en los municipios de interior se abre como una nueva oportunidad para algunos de ellos, pero no para todos. «El turismo no será nunca la panacea de todos los problemas de nuestros espacios rurales» (Ivars, 2000: 85). Únicamente unos pocos elegidos serán los que posean elementos de atracción suficientemente capaces de constituir verdaderas potencialidades, el resto se podrán aprovechar solamente de las irradiaciones generadas por estos municipios más atractivos como espacios de uso complementario o tránsito. De todos modos, siempre va a ser interesante la promoción conjunta de espacios supramunicipales complementarios, aún sabiendo que es complicado en la práctica, los municipios no deberían crear ofertas repetitivas que generen competencias entre sí, sino contribuir según tipos de oferta a un paquete lo más completo posible, agrupado bajo el nombre de una marca que le sea distintiva, reconocible y propia. Como se puede apreciar, a pesar de ser el turismo de interior el último en llegar a este juego de captación de afluencias y divisas, este posee un jugoso campo de labor e investigación. Debemos tener en cuenta que se enmarca sobre un espacio sin apenas explotar turísticamente, cual lienzo en blanco para el planificador. Si aún más cabe, por este motivo, se deben centrar mayormente nuestros mejores esfuerzos a la hora de desarrollar la más provechosa y correcta ordenación territorial, ahora si, basada en una clara y definida planificación estratégica de la cual no podremos eludir responsabilidad alguna.

\section{Objeto de estudio}

La finalidad de este artículo, no va a ser otra, que la de dar a conocer una delimitación correcta y objetiva, que diferencie los municipios que por un lado se han desarrollado turísticamente gracias al binomio sol-playa, de aquellos otros que lo están haciendo o pueden llegar a hacerlo bajo el estandarte del turismo de interior o rural.

A priori, puede parecer una labor simple si se conoce el espacio provincial, pero ya demostraremos que esta tarea es sumamente compleja, sobre todo si se pretende dotar a la selección de una serie de criterios de uniformidad basados en una óptica científica y objetiva.

Hemos de señalar, que hasta el momento no se ha esclarecido de un modo suficientemente claro, una delimitación del turismo de interior que aglutine a toda la provincia de Alicante. Todos conocemos municipios que son claramente litorales, así como también otros, que son fácilmente reconocibles como espacios de turismo interior. El problema viene dado con aquellos espacios que están a caballo entre los dos medios y se pretende esclarecer si dependen del espacio litoral para su desarrollo, o son independientes y aptos para la apuesta interior. 


\section{Metodología}

La labor de investigación la vamos a realizar sobre un espacio claramente definido, es decir, el ámbito que compete a la superficie territorial de la provincia de Alicante. Sin embargo, no se van a analizar las particularidades espaciales presentes en el interior de cada uno de los términos municipales, ni tampoco las pedanías que estos puedan contener, todo ello en pro de homogenizar una única conclusión para cada municipio. La clasificación se establecerá conforme a tres grupos principales:

\subsection{Municipios de vocación litoral}

Serán aquellos que basan su atractivo y reclamo turístico en el binomio sol-playa. A tenor de ello, podemos manifestar que todos los municipios costeros alicantinos, se hacen partícipes de una notable explotación turística en la mayoría de los casos derivada de este binomio. Sin embargo, debemos hacer salvedad en aquellos municipios de gran superficie territorial, como el caso de Elche y sobre todo Orihuela, que aunque es fundamental para su desarrollo turístico la presencia de fachada marítima, disponen a su vez de otros muchos encantos que pueden suscitar la visita de no sólo un turismo masivo de tipo litoral.

\subsection{Municipios inmediatos al litoral}

Vendrían a ser aquellos que sin ofertar el sol y la playa en su término municipal, se benefician claramente de los flujos de visitantes irradiados por el medio litoral. Este grupo lo podemos dividir a su vez en dos subgrupos:

\subsubsection{Municipios inmediatos al litoral de orden accesorio}

Se trata de municipios totalmente dependientes del litoral para su explotación turística, ya que actúan como verdaderas sucursales turísticas con el fin de diversificar la oferta complementaria del litoral o ampliar su disponibilidad de suelo destinado a un urbanismo de uso turístico. Por este motivo, deberemos considerar a estos municipios como de vocación turística litoral a efectos de planificación.

\subsubsection{Municipios inmediatos al litoral de orden ocasional}

Se trata de municipios interiores, pero que se benefician también de la llegada ocasional de visitantes provenientes del litoral, aunque si bien en este caso, sin llegar a constituirse una dependencia que afecte al propio desarrollo turístico. También incluiremos dentro de este grupo a aquellos municipios de sesgo mixto, que comparten por la gran extensión de su término municipal un modelo turístico litoral y otro interior. Estos municipios finalmente serán tratados como de vocación turística interior a efectos de planificación.

\subsection{Municipios de vocación turística interior}

Son aquellos prácticamente independientes al modelo turístico litoral, que constituyen un foco de atracción es sí mismos y que conservan su idiosincrasia rural o urbana poniéndola al servicio del turismo como elemento de reclamo. 
Para esclarecer la pertenencia de los municipios a cada uno de los grupos anteriormente aludidos, se va a tratar de analizar toda una serie de variables que se utilizarán posteriormente como argumentos de diferenciación municipal.

\section{Capas de información}

\subsection{Presencia de fachada marítima}

Se trata de vislumbrar cuales de los municipios alicantinos poseen costa alojada en su término municipal (vid. Fig. 1). Este será un factor de pertenencia al espacio turístico litoral, ya que supondrá una mayor o menor presencia de playas en su haber, susceptibles de atracción turística. De todos modos, no podemos decir que sea un factor del todo determinante por si mismo, ya que dependiendo del resto de resultados se verá si todos los municipios con costa son merecedores de ser considerados como de vocación turística litoral. Sirvan como ejemplo, municipios con fachada marítima como Orihuela y Elche, que por su gran superficie municipal poseen su ciudad alejada del frente costero.

\subsection{Análisis de la promoción turística}

Aquí se va a intentar averiguar que municipios sin fachada marítima se encuentran promocionados en la zona costera. Esto puede resultar también un factor de inclusión en el grupo de los municipios de vocación turística litoral, ya que los municipios interiores promocionados en el litoral pueden resultar receptores de flujos turísticos desplazados en pro del desarrollo de una oferta complementaria. Consideraremos por lo tanto a estos municipios como de vocación turística litoral si dependen exclusivamente de estos flujos para su viabilidad turística, ya que a pesar de no tener costa, pueden actuar como auténticas sucursales turísticas de los espacios litorales.

También es importante destacar, que ahora no todos los municipios interiores promocionados en el litoral van a formar parte del turismo litoral, esto vendrá en función de la relevancia y la capacidad de atracción del producto promocionado, así como también de la distancia a la cual se encuentren de la costa.

Para la creación de esta capa de información (vid. Fig. 2), se llevó a cabo un destacado y decidido trabajo de campo. En primer lugar, se acordó la elección de una sería de municipios costeros representativos del litoral turístico alicantino, en función de su máxima equidistancia territorial y relevancia turística. Finalmente, se optó por los municipios de Denia, Calpe, Benidorm, Alicante y Torrevieja. Sobre todos ellos, se realizó una minuciosa y laboriosa recolecta de los folletos turísticos promocionales y publicitarios expuestos en las oficinas de turismo y los hoteles más representativos de cada localidad.

\subsection{Análisis de la oferta de alojamiento}

A través del análisis de los datos publicados por el Servei d’Estudis i Planificació de la Agència Valenciana del Turisme, en su revista «Oferta Turística municipal y comarcal, 2002». Se procedió diferenciar modelizaciones típicas de oferta que nos pudieran indicar que espacios ofrecían alojamientos para turistas litorales y cuales para turistas rurales (vid. Fig. 3). Aunque no exacto, un rasgo distintivo del turismo litoral son la presencia de bloques de apartamentos, mientras que para el caso del turismo interior lo son las casas rurales. Esto nos concedió una herramienta más de apoyo para la diferenciación del espacio turístico provincial. 


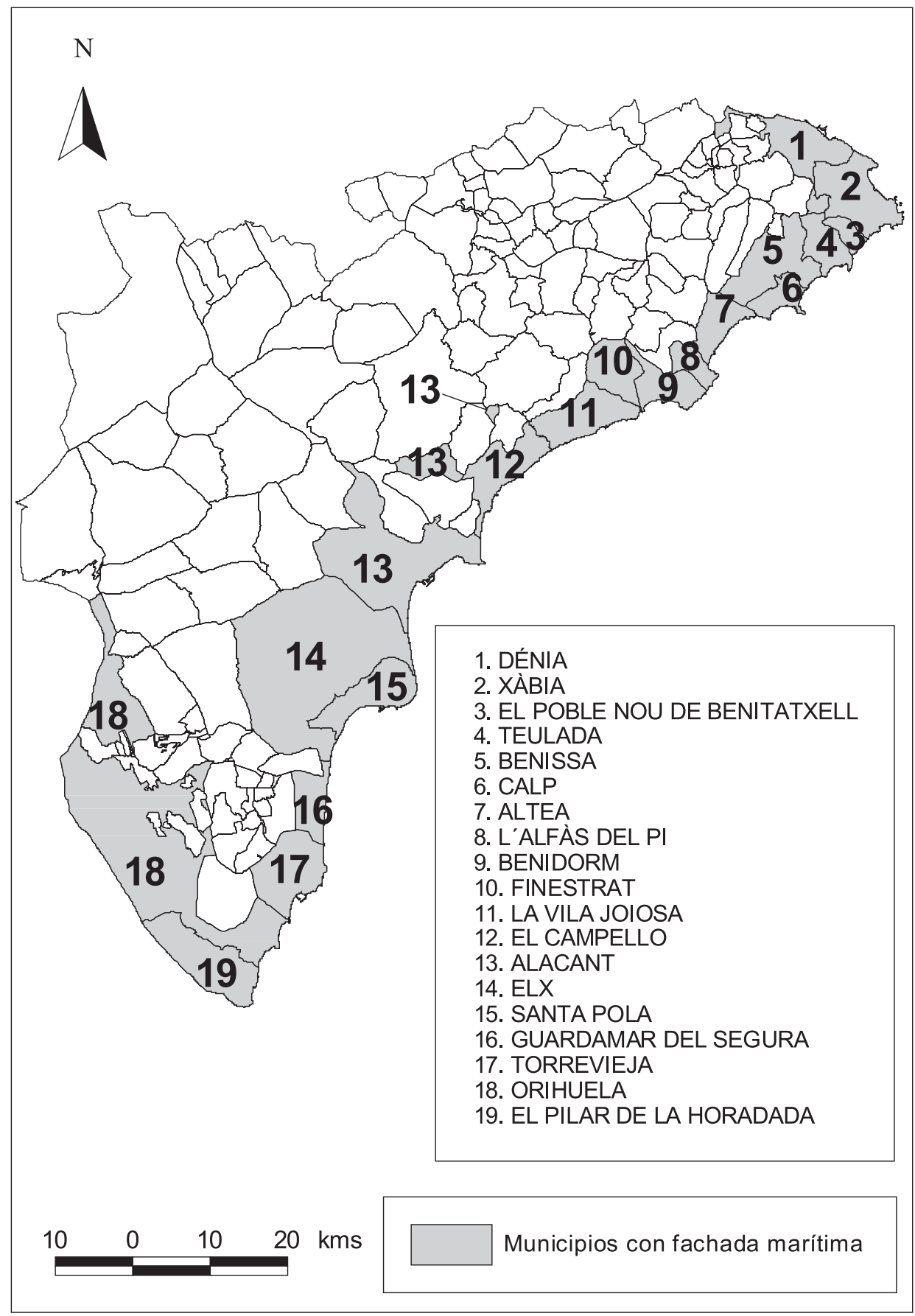

Figura 1. Municipios de la provincia de Alicante con fachada marítima Fuente: Elaboración propia a partir del análisis cartográfico municipal 


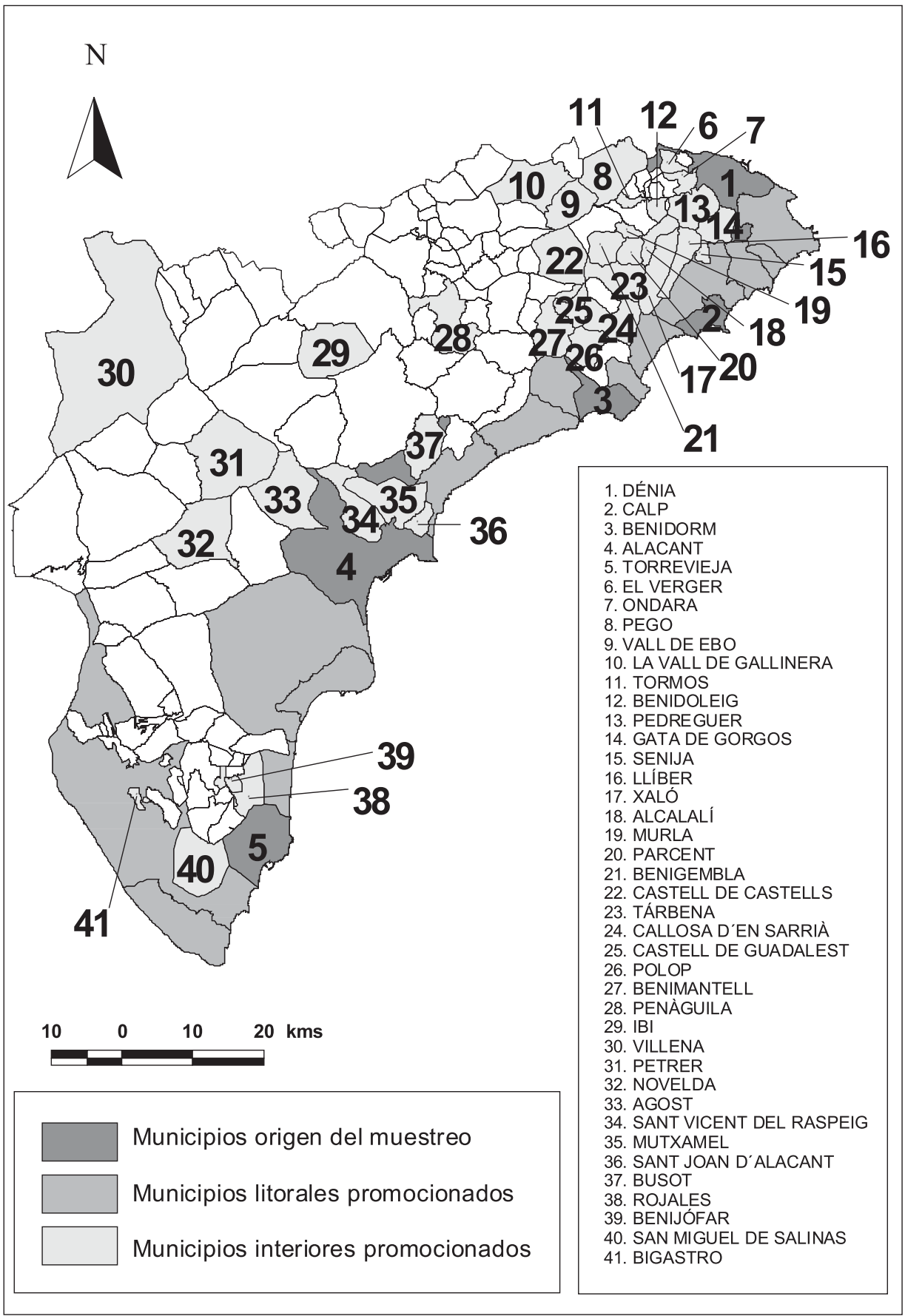

Figura 2. Municipios promocionados en el área litoral de la provincia de Alicante Fuente: Recogida de folletos promocionales y publicitarios en hoteles y oficinas de turismo 


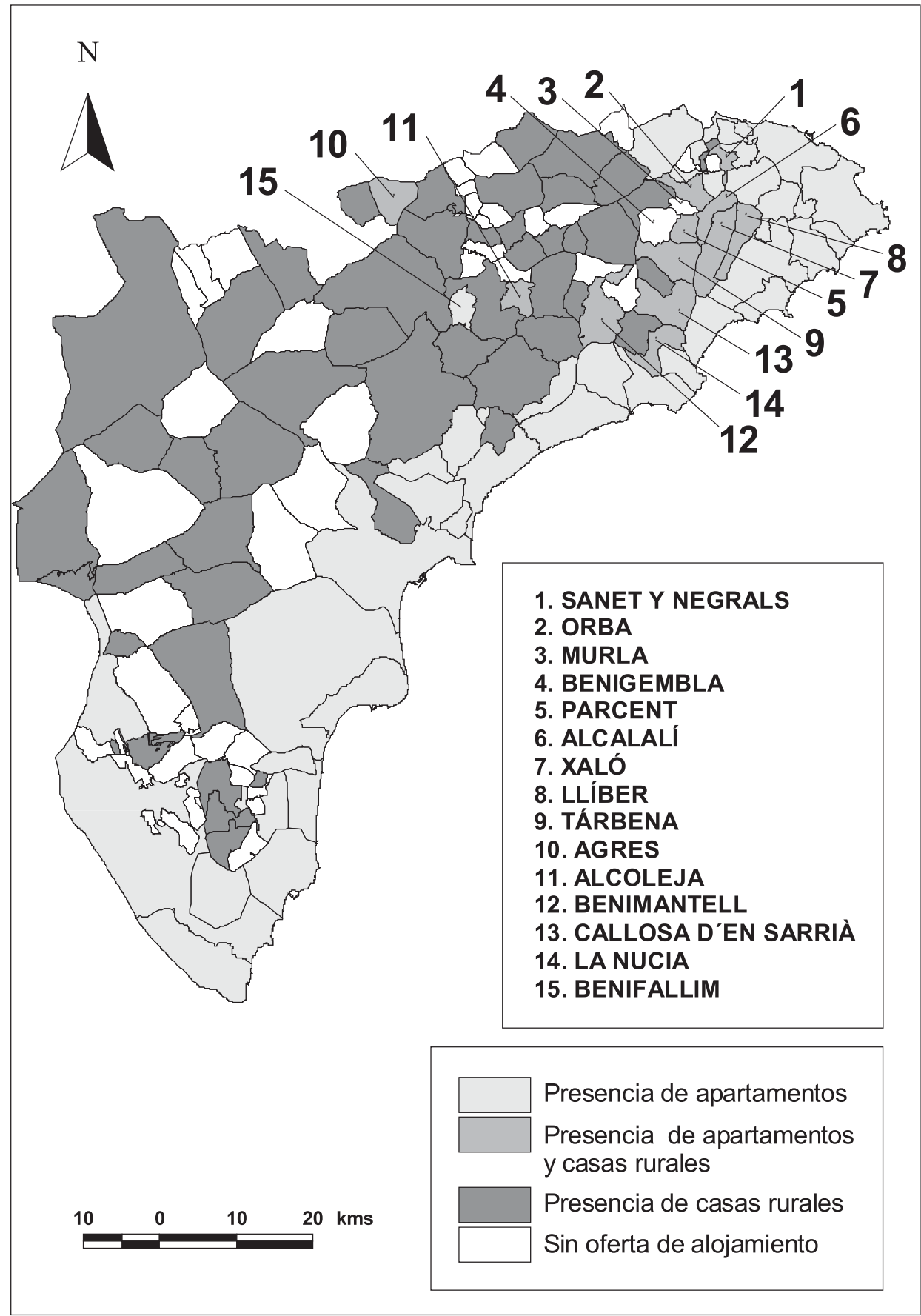

Figura 3. Tipos de oferta de alojamiento en la provincia de Alicante Fuente: Agència Valenciana del Turisme 


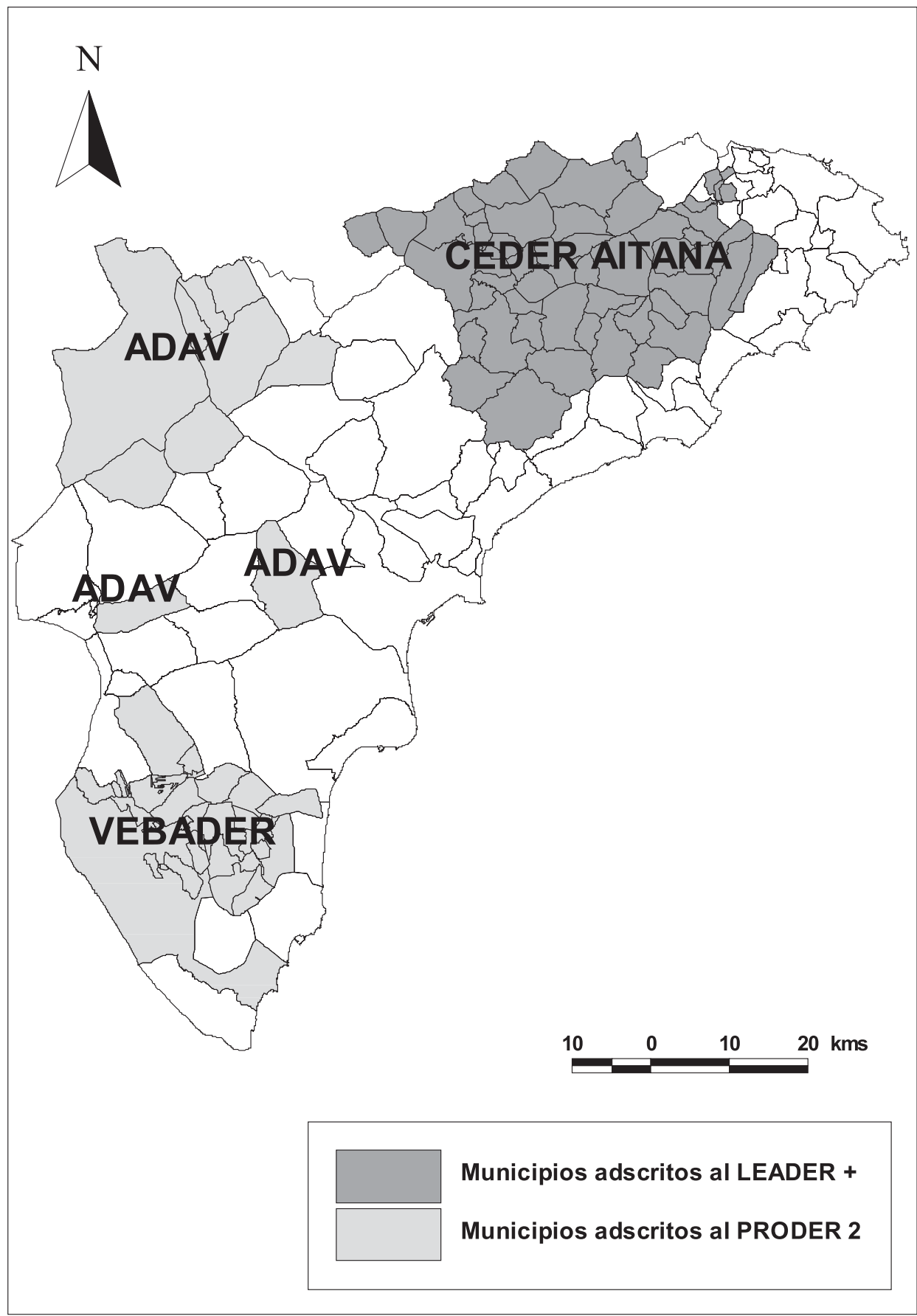

Figura 4. Programas de la U. E. para el desarrollo rural de la provincia de Alicante Fuente: CEDER AITANA, ADAV y VEBADER 


\subsection{Existencia de programas europeos para el desarrollo rural}

La existencia de estos programas europeos va a constituir un factor de exclusión del ámbito turístico litoral, ya que los espacios desarrollados gracias al turismo de masas han perdido ya su vocación rural y no son merecedores de ayudas comunitarias para el desarrollo endógeno. Mientras tanto, los municipios que se incorporan a estos programas de apoyo (vid. Fig. 4), tienen entre sus estrategias de revitalización y desarrollo de complementos económicos la firme apuesta por el turismo rural.

Los programas que se han tenido en cuenta para la creación de esta capa de información han sido el PRODER 2 y el LEADER +. En este sentido, cabe señalar que existen dos asociaciones dependientes del PRODER 2, por un lado ADAV (Asociación para el Desarrollo del Alto Vinalopó) y por el otro VEBADER (Vega Baja Desarrollo Rural). Por su parte, la gestión de los fondos del LEADER + corre a cargo del CEDER-AITANA.

\section{Argumentos para la delimitación provincial}

En este apartado, vamos a establecer la clasificación de los municipios de la provincia de Alicante, según la pertenencia a cada uno de los grupos creados. Hemos de indicar, que sólo apuntaremos en obligada síntesis, los motivos de clasificación de aquellos municipios más difíciles de discernir, es decir, los inmediatos al litoral de orden accesorio y ocasional.

\subsection{La comarca de la Marina Alta}

\subsubsection{Municipios inmediatos al litoral de orden accesorio}

Benidoleig: Este municipio contribuye a ampliar la oferta complementaria de los municipios litorales, ya que su Cueva de las Calaveras aparece promocionada por prácticamente todo el litoral alicantino. Además de ello, se encuentra aún dentro del área de máximo desplazamiento de los turistas litorales por situarse relativamente cerca de la costa, a unos $48 \mathrm{kms}$ de Benidorm. No forma parte de ningún programa europeo para el desarrollo rural y además oferta 21 apartamentos.

Gata de Gorgos: Participa en la ampliación de la oferta complementaria de los municipios litorales, ya que es el destino del popular tren turístico que sale de Benidorm, el «Lemon Expres». También es frecuente la captación de visitantes a través de folletos que ofertan la artesanía típica del lugar, es decir, mimbres y guitarras fundamentalmente. Se encuentra además dentro del área de máxima movilidad de los turistas litorales por ubicarse relativamente próximo al espacio litoral, a unos $45 \mathrm{kms}$ de Benidorm. Por otro lado, resaltaremos que tampoco forma parte de ningún programa europeo para el desarrollo rural y presenta en su municipio 2 apartamentos.

Ondara: Contribuye a ampliar la oferta complementaria de los municipio litorales vecinos, por un lado capta la visita de turistas a través de un «Go kart and cross buggy» y por el otro mediante sus bodegas vitivinícolas. El municipio se encuentra adosado a Denia y aunque su actividad económica prioritaria es la agricultura de cítricos, cada vez está apostando más por el sector servicios beneficiado por la irradiación de turistas provenientes del litoral. No forma parte de ningún programa europeo para el desarrollo rural y dispone en su haber la oferta de 6 apartamentos.

Pedreguer: Engrosa la oferta complementaria de los municipios litorales vecinos, ya que dispone de un centro de equitación en la urbanización «La Sella». También es importante la oferta en artesanía, especializada en bolsos, sombreros y marroquinería. Pero debemos 
señalar, que el hecho que más nos ha influido a la hora de clasificar este municipio como accesorio del litoral, ha sido la amplia oferta de apartamentos que ofrece con un total de 180. La razón de esta profusión de apartamentos la encontramos en que Pedreguer linda con Denia, de modo que este municipio a apostado por consumir el suelo de Pedreguer, dado su menor coste económico y su relativa proximidad al mar. Además de todo lo anterior, hemos de señalar que el municipio en cuestión no está incluido en ningún programa europeo para el desarrollo rural.

Pego: Incrementa la oferta complementaria de los municipio litorales, ya que posee el Parque Natural de la Marjal de Pego-Oliva. Pero lo más significativo, al igual que en el caso de Pedreguer, es la abundancia de apartamentos surgidos al amparo de la cercanía al mar. Pego presenta como censados un total de 137 apartamentos. Por último, nos queda solamente apuntar que este municipio no forma parte de ningún programa de la Unión Europea para el desarrollo rural.

Els Poblets: Es un municipio pequeño de 1.688 habitantes, que se encuentra ubicado al amparo de Denia y a pesar de no poseer costa es como si la tuviera, ya que la línea marítima se encuentra muy próxima. Su realidad turística es similar a la de Denia, ya que presenta a pesar de su reducido tamaño urbanizaciones de extranjeros residentes todo el año e incluso hoteles. Concretamente, en este municipio aparecen un total de 50 apartamentos. También debemos indicar que no pertenece a ningún programa europeo para el desarrollo rural.

Senija: Tradicionalmente este municipio se ha dedicado al cultivo de cítricos y olivos, pero en la actualidad, se ha subido también al tren del turismo de la mano de su municipio vecino, Benissa. De este modo, solamente se entiende que a pesar de tratarse de un municipio con 509 habitantes, posea ya 7 apartamentos. Además, indicar que a pesar de su reducido tamaño, no forma parte de ningún programa europeo para el desarrollo rural.

El Verger: Contribuye a ampliar la oferta complementaria de los municipios litorales, ya que en su término se ubica el Safari Park Vergel promocionándose por todo el litoral alicantino. También capta la llegada de visitantes, aunque en menor medida, gracias a un parking de caravanas y embarcaciones. Además de ello, por su relativa proximidad al litoral, presenta en su haber, un total de 4 apartamentos. Para finalizar, no debemos olvidar, que este municipio tampoco está incluido en ningún programa europeo de desarrollo rural.

\subsubsection{Municipios inmediatos al litoral de orden ocasional}

Alcalalí: Se trata de un municipio interior que recibe cierta afluencia ocasional de visitantes provenientes del litoral, ya que se establecen promociones de este municipio basadas en la oferta de excursiones, alojamientos y restaurantes. Es de destacar asimismo la promoción que se realiza de sus bodegas de vinos y licores, aunque de igual forma sea relevante su artesanía en mimbres y muebles. La oferta de alojamiento de Alcalalí se basa fundamentalmente en 10 apartamentos y una casa rural. Este municipios se encuentra ubicado próximo al litoral, a tan sólo $42 \mathrm{kms}$ de Benidorm. Para finalizar, podemos indicar que Alcalalí formó parte del LEADER II en su día y que en la actualidad pertenece al LEADER +.

Xaló: La capital de la Vall del Pop es un municipio con todos los rasgos necesarios para clasificarse como municipio de vocación turística interior. Xaló no se promociona en el litoral y ha ingresado recientemente en el programa europeo para el desarrollo rural LEADER +. Lo que sucede, es que se ubica muy próximo a los municipios costeros, los cuales, irradian irremediablemente visitas ocasionales sobre todo provenientes de sus vecinos Benissa y Altea, aunque también Calpe y Benidorm que solamente se encuentra a 34 kms de distancia. En un futuro, tendrá que posicionarse turísticamente como un municipio 
interior o un accesorio del litoral. De momento, se mantiene a la expectativa tratando de aprovechar todo el turismo que le llega, presentando como oferta de alojamiento 24 apartamentos y dos casas rurales.

Parcent: A este municipio le sucede algo similar al caso anterior, aunque se encuentra bastante más alejado de la costa. Se puede considerar como un municipio de vocación turística interior, ya que no se promociona mucho en el litoral y ha ingresado hace poco en el LEADER +. Tradicionalmente, se trata de un municipio de vocación agrícola, dedicado en primacía al cultivo de almendros y cítricos, aunque en la actualidad, una parte importante de sus 857 habitantes, trabaja en la costa para el sector servicios sin abandonar su residencia en la localidad. Las visitas provenientes del litoral suelen ser de tipo diario, aunque se ofrece la posibilidad de alojarse en 6 apartamentos y una casa rural.

Ráfol de Almunia: Este pequeño municipio de solamente 402 habitantes, aprovecha su proximidad al litoral captando la llegada de turistas ocasionales que no les importa desplazarse unos kilómetros de las playas, a cambio de estar un poco más tranquilos. Posee un total de 14 apartamentos y podría considerarse como un municipio accesorio, si no fuera por que no establece promoción alguna en el litoral y en la actualidad se ha incorporado al LEADER +. Entendemos que pretende compatibilizar el turismo rural con la captación de flujos turísticos litorales esporádicos, sin llegar a convertirse en una sucursal del ámbito costero.

Vall de Ebo: A pesar de que este municipio está muy promocionado en el litoral, destacando para el caso su Museo Etnográfico y sobre todo la Cova del Rull, no intenta convertirse en una mera sucursal que aumente el abanico de oferta complementaria litoral. Está claro, que aceptará de buen grado las visitas diarias de turistas alojados en el medio litoral, pero lo que realmente quiere es afianzar su turismo rural como demuestra la posibilidad de alojarse en tres casas rurales ya existentes. Además de ello, debemos resaltar que este municipio ya formaba parte del LEADER II y en la actualidad lo sigue haciendo de su versión plus.

\subsection{La Comarca de la Marina Baixa}

\subsubsection{Municipios inmediatos al litoral de orden accesorio}

Callosa d'En Sarrià: A pesar de que este municipio apuesta también por el turismo rural, como en cierto modo demuestra la existencia de cuatro casas rurales y la inclusión desde el principio en el LEADER II y ahora en el LEADER +. Su explotación turística debemos decir, que hoy por hoy, es plenamente dependiente de las visitas procedentes de la costa en busca de una diversificación de la oferta complementaria litoral. El elemento de diversificación lo constituye fundamentalmente las Fuentes del Algar y su Cactus d'Algar Jardí Botanic. A este fenómeno, contribuye en gran medida el fácil acceso desde el litoral, ya que se ubica a solamente $10 \mathrm{kms}$ de Benidorm.

Castell de Guadalest: Este municipio constituye el ejemplo prototípico de municipio accesorio del litoral. Actúa como una verdadera sucursal turística para diversificar la oferta complementaria de Benidorm primordialmente. Lo más llamativo, es que no ofrece ninguna posibilidad de alojamiento, todas las visitas son diarias, se trata de excursiones que pretenden la visita al castillo, la iglesia, los museos y los comercios, para una vez llegada la noche volver a pernoctar al municipio litoral de origen. A esto, contribuye decisivamente la proximidad a la costa, ya que se sitúa a tan sólo $22 \mathrm{kms}$ de Benidorm. A pesar de todo, debemos señalar que este municipio formó ya parte del LEADER II y en la actualidad lo hace del LEADER +. 
La Nucia: Se trata también de un claro ejemplo de municipio accesorio del litoral, pero no por las promociones que realicen en el litoral, ni las visitas que se susciten. Aunque tiene cierto carácter de convocatoria el rastrillo que se realiza los domingos por la mañana de objetos usados y demás géneros. Lo fundamental, para incluir el municipio en este grupo, es la presencia de 69 urbanizaciones de residentes nacionales y extranjeros, que las ocupan durante todo el año, así como también la oferta de 47 apartamentos y una casa rural. El motivo de este desarrollo se tiene que buscar en la proximidad a la línea de costa, y fundamentalmente a Benidorm, del cual dista tan sólo $10 \mathrm{kms}$. Por último, cabe señalar que este municipio, no forma parte de ningún programa europeo para el desarrollo rural, ya que ha crecido en los últimos años progresivamente hasta llegar a sus 8.616 habitantes.

\subsubsection{Municipios inmediatos al litoral de orden ocasional}

Benimantell: Este es un municipio de corte mixto, que aunque posee todos los elementos necesarios para ser un municipio de plena vocación turística interior, es decir, un pueblo de 415 habitantes, ubicado en la umbría de la sierra de Aitana y dedicado tradicionalmente a la agricultura de secano (olivos y almendros), que posee cinco casas rurales, un apartamento y además forma parte del LEADER +. Hemos de señalar, que recibe también la llegada ocasional de visitantes procedentes del litoral, dada la promoción que se establece de su ruta zoológica y botánica «El Arca», como un elemento de diversificación de la oferta complementaria litoral. A la llegada de visitantes contribuye asimismo la relativa proximidad de Benimantell al litoral, ya que se encuentra adosado al municipio de Finestrat.

Polop: Es un municipio de vocación turística interior, como demuestra la presencia de sus tres casas rurales y la pertenencia al LEADER +. Pero que por su cercanía a la costa, ubicado únicamente a $11 \mathrm{kms}$ de Benidorm y la promoción en el litoral de su artesanía en zapatos y botas de piel, recibe la llegada ocasional de visitantes alojados en el ámbito costero. Éstos una vez allí, además pueden admirar el tipismo urbano blanco y azul de este pueblo de 2.136 habitantes.

\subsection{La Comarca del Comtat}

Después de analizar las variables de los municipios de esta comarca, hemos llegado a la conclusión de que todos los municipios presentes en ella pueden considerarse como de vocación turística interior. Los motivos de tal determinación, radican en la conformación de una oferta de alojamiento basada fundamentalmente en casas rurales, la total inclusión en el programa europeo LEADER II y posteriormente en el LEADER +, la lejanía a la costa y la plena inexistencia de promoción turística en el litoral alicantino.

\subsection{La Comarca de l'Alcoià}

\subsubsection{Municipios inmediatos al litoral de orden ocasional}

Penàguila: A este municipio de interior simplemente lo incluimos en este grupo por la gran promoción que se establece en el litoral de su Safari Aitana, como un elemento fundamental en la diversificación de la oferta complementaria litoral, que hace que ocasionalmente reciba visitas de turistas alojados en el medio costero. El resto de las variables analizadas son las típicas de un municipio interior, es decir, una oferta de alojamiento basada en la existencia de una casa rural, un hostal y un albergue, la inclusión desde el principio en el programa europeo LEADER II y en la actualidad en el LEADER +, una población 
pequeña de tan sólo 391 habitantes y su asentamiento en la vertiente occidental de la sierra de Aitana, lo suficientemente alejado de la costa como para no llegar a convertirse en un municipio accesorio del litoral.

A pesar de que Ibi ofrece la promoción de su Museu del Joguet en el litoral, consideramos que este municipio está demasiado alejado de la línea de costa como para generar un volumen de visitas importante provenientes de este espacio. Por este motivo, lo descartamos como municipio inmediato al litoral de orden ocasional.

\subsection{La Comarca de l'Alacantí}

\subsubsection{Municipios inmediatos al litoral de orden accesorio}

Busot: Se trata de un pequeño municipio de tan sólo 1.717 habitantes, de tradicional vocación agrícola, pero que en la actualidad vive en gran parte de las visitas que recibe provenientes del litoral. Sus Cuevas de Canelobre, constituyen uno de los principales elementos en la diversificación de la oferta complementaria de los municipios litorales. Busot, se sitúa en la parte sur del Cabeço d’Or, a tan sólo $19 \mathrm{kms}$ de Alacant y a $45 \mathrm{kms}$ de Benidorm, haciendo linde con los términos de El Campello y Alacant. Debemos apuntar, que este municipio presenta como oferta de alojamiento tres apartamentos y además no forma parte de ningún programa europeo para el desarrollo rural.

Mutxamel: Este municipio se encuentra ubicado sobre las tierras de aluvión del río Monnegre, lo que lo hace ideal para el desarrollo de una agricultura de vanguardia. Por otro lado, su vecindad con Sant Joan d'Alacant, El Campello y sobre todo Alacant, del cual se ubica a tan sólo $7 \mathrm{kms}$. Ha encaminado un desarrollo turístico debido al desbordamiento urbanístico del suelo litoral, que ha llevado a creación de 42 apartamentos, un camping, un hotel y una casa rural. Además, la configuración de un elemento de diversificación de la oferta complementaria litoral, es decir, el club de hípica y el campo de Golf Bonalba, de fácil aparición en folletos promocionales dispuestos en el ámbito litoral, acaban por posicionar a este municipio como un accesorio del litoral. Añadir si cabe como argumento, el hecho de que no considera necesario pertenecer a ningún programa europeo para el desarrollo rural.

Sant Joan d'Alacant: El único hecho por el cual no consideramos a este municipio de 14.693 habitantes como litoral puro, se debe a que en su término municipal no se dispone de fachada marítima. Por este motivo, lo clasificaremos como municipio inmediato al litoral de tipo accesorio. Este municipio posee las características de cualquier municipio costero alicantino, utilizando como suya, la playa que con el nombre de San Juan posee el término municipal de Alacant. El municipio presenta como oferta de alojamiento un total de cuatro hoteles, seis apartamentos y un camping. Mientras que por descontado, no se incorpora en las filas de ningún programa europeo para el desarrollo rural.

\subsubsection{Municipios inmediatos al litoral de orden ocasional}

Agost: A pesar de que este municipio aspire a convertirse en un municipio accesorio del litoral en un futuro, por encontrarse adosado al término municipal de Alacant, ciudad de la que dista en tan sólo $18 \mathrm{kms}$. De momento, únicamente podemos decir, que presenta una vaga vocación turística, dedicándose esencialmente a la cerámica y a la uva de mesa embolsada, ya que no presenta oferta alguna de alojamiento. La única opción reseñable como turística, es la que se puede operar por la promoción en el litoral de su Museo de Alfarería, que puede inspirar alguna visita ocasional de poca entidad. Por otro lado, debe- 
mos señalar que nos parece extraño que este municipio de tan sólo 4.095 habitantes, no pertenezca todavía a ningún programa europeo para el desarrollo rural.

\subsection{La Comarca de l'Alt Vinalopó}

En esta comarca todos sus municipios, es decir, Beneixama, Biar, Camp de Mirra, Cañada, Salinas, Sax y Villena pueden considerarse tras el análisis de sus variables como municipios de plena vocación turística interior. La única pega por así decirlo, radica en la promoción que se realiza de los museos de Villena en el litoral. A pesar de ello, no podemos decir que tal promoción vaya a generar un flujo importante y constante de visitantes provenientes del litoral, ya que el elemento promocionado no posee el suficiente interés por si sólo como para ser capaz de salvar el escollo de los más de $50 \mathrm{kms}$ que lo separan de Alacant.

\subsection{La Comarca del Vinalopó Mitjà}

$\mathrm{Al}$ igual que en el caso anterior, los municipios que conforman esta comarca, es decir, Algueña, Aspe, Elda, Hondón de las Nieves, Hondón de los Frailes, Monforte del Cid, Monòver, Novelda, Petrer, Pinoso y La Romana son de vocación turística interior. Las promociones establecidas en el litoral tanto de Novelda, con un folleto de tipo general que habla de los monumentos, los parques y las fiestas. Como el de Petrer, referido a senderos de pequeño recorrido. No son lo suficientemente significativos como para suscitar desplazamientos relevantes desde el litoral, más aún, si consideramos la distancia a salvar desde la costa.

\subsection{La Comarca del Baix Vinalopó}

El caso de Elx es el más difícil de discernir, en principio parece que obedece al modelo seguido por los municipios de vocación turística litoral, dada su tipología de oferta de alojamiento. Sin embargo, debemos tener en cuenta que es un municipio con un gran término municipal, que abarca diferentes espacios y que puede diversificar el turismo de interior alicantino, dados sus numerosos atractivos y encantos ajenos al binomio sol-playa. Por este motivo, hemos decidido incorporarlo a la clasificación como un municipio de sesgo mixto, bajo el calificativo de municipio inmediato al litoral de orden ocasional.

\subsection{La Comarca del Bajo Segura}

\subsubsection{Municipios inmediatos al litoral de orden accesorio}

Rojales: Se trata de un claro ejemplo de municipio accesorio del litoral, ya que supone una prolongación turística del propio municipio de Torrevieja, justificada por la tremenda necesidad de suelo disponible que presenta este municipio costero. Aunque de momento, este enclave solamente ofrece la posibilidad de alojarse en un hotel de novedosa factura o en un apartamento, los apéndices del modelo turístico de Torrevieja se van ampliando en forma de urbanizaciones. En el litoral, se promociona Rojales ya como si formara parte de Torrevieja, tanto en la oferta de servicios, como en disponibilidad de empresas dedicadas al sector turístico. Sirva como ejemplo, la promoción encontrada de un centro de buceo, aunque también se dispone del club de Golf La Marquesa, un aeroclub y una escuela de ultraligeros. A pesar de todo, debemos señalar que Rojales, forma aún parte del programa 
europeo para el desarrollo rural PRODER 2, ya que no debemos olvidar que se trata de un municipio de 7.321 habitantes.

San Fulgencio: A este municipio le sucede algo parecido a Rojales, pero en este caso, por su proximidad a Guardamar del Segura, a una escala inferior. En el momento actual, no se aprecia a grandes rasgos una gran explotación turística en este municipio, ya que presenta exclusivamente dos apartamentos como oferta de alojamiento. Sin embarco, es sólo cuestión de tiempo, que acabe por incorporarse plenamente al modelo turístico litoral como un nuevo anexo. San Fulgencio, está modificando su actividad agrícola en pro del sector servicios y se está dotando de nuevas infraestructuras. A pesar de todo, esta localidad de 3.706 habitantes, de momento, sigue perteneciendo al PRODER 2.

San Miguel de Salinas: Este municipio constituye la otra prolongación elegida por Torrevieja para expandirse territorialmente. En principio, presenta ya como oferta de alojamiento un total de 11 apartamentos, pero se prevé que siga creciendo. A modo anecdótico, diremos que encontramos ya en el litoral la promoción de una librería de lengua inglesa inserta en esta localidad. Como en el caso anterior, debemos señalar que este municipio de 3.893 habitantes también sigue formando parte del programa europeo para el desarrollo rural PRODER 2.

\subsubsection{Municipios inmediatos al litoral de orden ocasional}

Benijófar: Este pequeño municipio de tan sólo 1.866 habitantes y reducido término municipal, únicamente $4^{\prime} 4 \mathrm{~km}^{2}$, a pesar de no poseer oferta de alojamiento, ha tratado de captar visitantes procedentes del litoral repartiendo folletos turísticos por los municipios costeros próximos sobre su historia, fiestas, tradiciones, gastronomía y calidad de vida. Por este motivo, no es del todo descabellado pensar que pueda recibir flujos turísticos ocasionales procedentes del ámbito costero. A pesar de todo, parece ser, que lo que pretende es apostar por el turismo rural pero con la captación de flujos turísticos litorales, como parece demostrar su pertenencia al programa europeo para el desarrollo rural PRODER 2.

Orihuela: En este municipio sucede lo mismo que en Elx, al poseer fachada marítima se aprovecha de un turismo de tipo litoral, aunque sobre todo se hace destacable el consumo de suelo para uso residencial. Ello se evidencia, en su tipología de oferta de alojamiento, con 358 apartamentos y cuatro hoteles. Pero como se trata de un municipio con una enorme extensión territorial, que abarca varios ámbitos, también es muy importante para el turismo de interior en la provincia de Alicante, evidencia que se vislumbra con la presencia de casas rurales y su adscripción al PRODER 2, a pesar de poseer 53.478 habitantes. Por este motivo, lo calificaremos como un municipio de sesgo mixto, bajo la figura de municipio inmediato al litoral de orden ocasional.

\section{Conclusiones}

A pesar de haber logrado establecer una clasificación útil y objetiva, debemos hacer notar que cada vez es mayor el grado de imbricación entre el turismo litoral y el turismo interior. Las relaciones simbióticas entre ambos espacios son cada vez más intensas, lo que nos hace pensar que al final, gracias a la sobresaliente mejora de las vías de comunicación y la consiguiente reducción de las isócronas de desplazamiento, el espacio turístico provincial acabe articulándose como un todo lleno de particularidades competitivas.

De momento, gracias a la delimitación territorial de este proyecto (vid. Fig. 5) podemos empezar a operar una ordenación territorial y una planificación estratégica para todo el turismo de interior alicantino. Para este fin, se propone emprender una ordenación territorial 


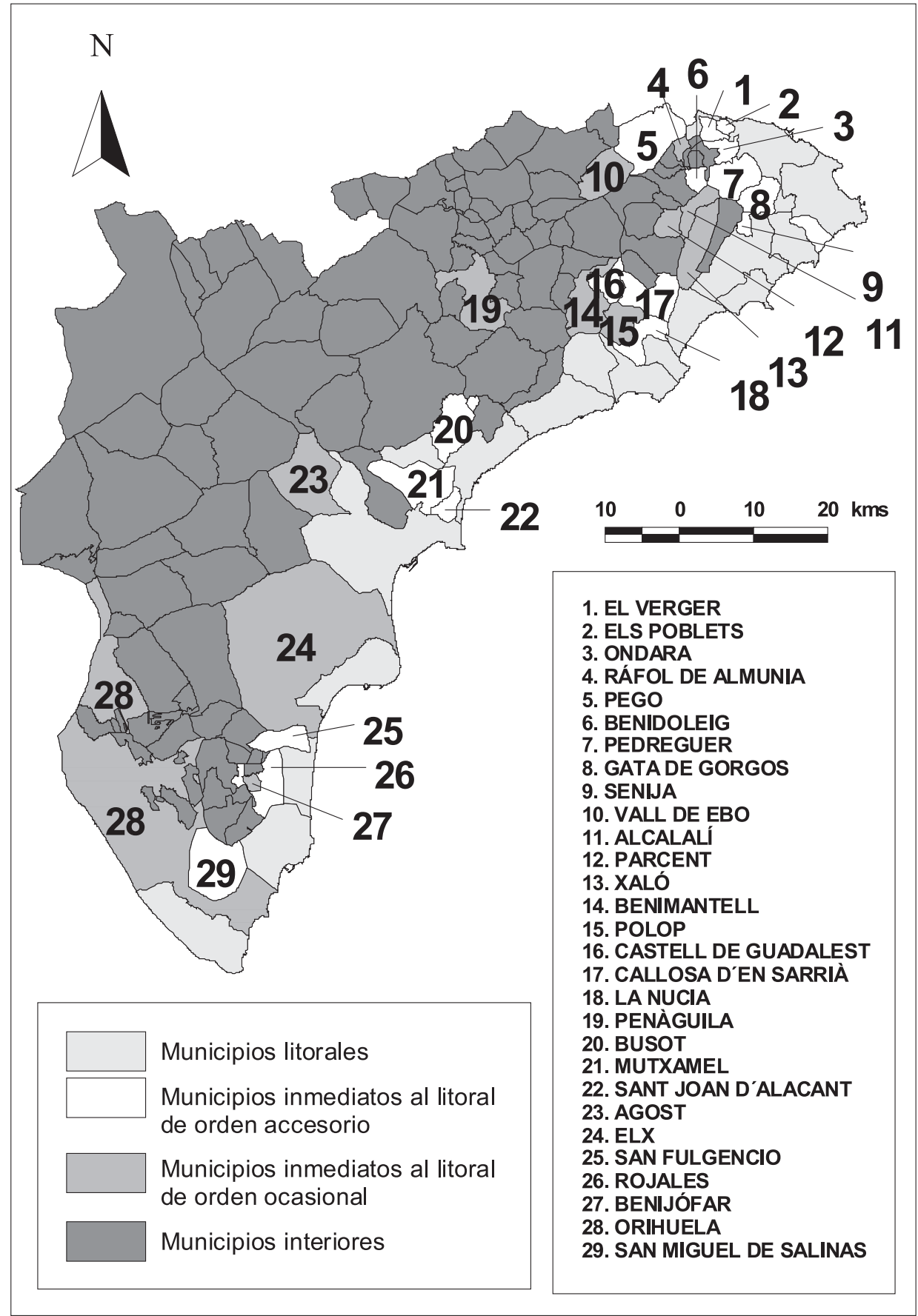

Figura 5. Delimitación municipal de los modelos turísticos en la provincia de Alicante Fuente : Elaboración propia a partir del análisis de las variables obtenidas 
basada en los archifamosos clusters de M. Porter, adaptados al espacio interior alicantino en función de agrupaciones supramunicipales basadas en la búsqueda de la máxima ventaja competitiva, la innovación productiva, la complementariedad intermunicipal y la creación marcas distintivas bien jerarquizadas.

Siguiendo esta idea, debemos indicar, que ya se están llevando a término iniciativas a este respecto en el interior alicantino, como demuestra la reciente creación (marzo, 2005) de una asociación de empresarios turísticos, la «Asociación de Turismo de Interior de la Foia» (ATIF), integrada por los municipios de Biar, Castalla, Ibi, Onil y Tibi.

En definitiva, se trata de apostar por el turismo de interior como una nueva opción de futuro para los municipios rurales, aglutinando potencialidades dispares e inconexas en forma de destinos turísticos bien organizados y competitivos, que den por qué no, un nuevo impulso catalítico al turismo provincial para desmarcarse de nuevo en los mercados nacionales e internacionales.

\section{Bibliografía}

AGÈNCIA VALENCIANA DEL TURISME (2003): «Oferta Turística municipal y comarcal, 2002». Servicio de Estudios y Planificación. pp. 73.

BAÑOS CASTIÑEIRA, C. J. (1998): «La oferta turística complementaria en los destinos alicantinos: implicaciones territoriales y opciones de diversificación». Investigaciones Geográficas, $\mathrm{n}^{\circ}$ 19. pp. 85-103.

BAÑOS CASTIÑERIRA, C. J. (1999): «Modelos turísticos locales. Análisis comparado de dos destinos de la Costa Blanca». Investigaciones Geográficas, n 21. pp. 35-57.

IVARS BAIDAL, J. A. (1996): «Análisis del potencial desarrollo turístico integrado de la Montaña de Alicante». Memoria de Licenciatura. Departamento de Análisis Geográfico Regional. Universidad de Alicante. pp. 321.

IVARS BAIDAL, J. A. (2000): «Turismo y espacios rurales: conceptos, filosofías y realidades». Investigaciones Geográficas, $\mathrm{n}^{\circ}$ 23. pp. 59-88.

OLCINA SOLER, L. Y SANCHIS SILVESTRE, A. (1995): «El desarrollo del Turismo Rural y sus Repercusiones» en Papers de Turisme. Ed. ITVA, Institut Turistic Valencià. pp. 89-101.

PORTER, M. E. (1998): «Cluster and the New Economics of Competition», Harvard Business Review. pp. 77-90.

SANCHO CARBONELL, I. (2001): «El enfoque territorial del desarrollo rural. Una aproximación al desarrollo rural en el ámbito de actuación del Ceder Aitana-Leader II (Alicante)» en El desarrollo rural/local integrado y el papel de los poderes locales. pp. 371-394.

SOLSONA MONZONIS, J. (1999): «El Turismo Rural en la Comunidad Valenciana: Análisis y Planificación. Aplicación al Alto Mijares». Sociedad Castellonense de Cultura. Castelló de la Plana. pp. 225.

VERA REBOLLO, J. F. (1984): «Mutaciones espaciales producidas por el turismo en el municipio de Torrevieja». Memoria de Licenciatura. Investigaciones Geográficas, $\mathrm{n}^{\circ}$ 2. pp. 114-139.

VERA REBOLLO, J. F. (2000): «El papel del turismo en el desarrollo local: Algunas consideraciones para los municipios rurales» en Eines per al desenvolupament local. Ed. CEDER-AITANA, pp. 217-232.

YEPES PIQUERAS, V. (1995): «Turismo Sostenible en el Interior de la Comunidad Valenciana: posibilidad de un desarrollo turístico complementario al del $<<$ sol y playa $>\gg$ en Papers de Turisme. Ed. ITVA, Institut Turistic Valencià. pp. 75-87. 